\title{
Farming Differentiation in the Rural-urban Interface of the Middle Mountains, Nepal: Application of Analytic Hierarchy Process (AHP) Modeling
}

\author{
Gopal Datt Bhatta (Corresponding author) \\ Institute of Agricultural Economics and Social Sciences (Institute 490C) \\ University of Hohenheim, 70593 Stuttgart, Germany \\ Tel: 49-176-2848-6343Ｅ-mail: bhattagopal@gmail.com \\ Werner Doppler \\ Institute of Agricultural Economics and Social Sciences (Institute 490C) \\ University of Hohenheim, 70593 Stuttgart, Germany \\ Tel: 711-4592-2514 E-mail: doppler@uni-hohenheim.de
}

\begin{abstract}
This article investigates the dominant factors of farming differentiation in the rural-urban interface of the densely populated Kathmandu Valley, using the Analytic Hierarchy Process (AHP) modeling. The rural-urban interface in the Kathmandu Valley is an important vegetable production pocket which supplies a large amount of the vegetables in the city core. While subsistence farming in the rural area is characterized by a system which integrates livestock and forestry with agriculture, the intensification in the urban fringe is characterized by triple crop rotations and market-oriented intensive vegetable production. Seven factors which were supposed to cause farming variation in the interface were incorporated in the AHP framework and then subjected to the farmers' judgment in distinctly delineated three farming zones. These factors played crucial yet differing roles in different farming zones. Inaccessibility and use of local resources; higher yield and accessibility and agro-ecological consideration and quality production are the key impacting factors of subsistence, commercial inorganic and smallholder organic farming respectively. The quantification of such factors of farming differentiation through AHP is an important piece of information that will contribute in modeling farming in the rural-urban interface of developing countries which are characterized by a high diversity of farming practices and are undergoing a rapid change in the land use pattern.
\end{abstract}

Keywords: AHP, Farming differentiation, Kathmandu Valley, Nepal, Rural-urban interface

\section{Introduction}

The Middle Mountains of Nepal occupy about $30 \%$ of the total land (Jodha, 1995), covering $42 \%$ of the area and accommodating $44 \%$ of the total population (Pradhan, 2003), including densely populated Kathmandu Valley which contains $31 \%$ of the total urban population of Nepal (Thapa and Murayama, 2010). This Valley and its surroundings are blessed with varied production practices, socio-economic and bio-physical make ups. The fulfillment of subsistence requirements has been the primary objective of the majority of the farmers in the Middle Mountains since centuries (Carson, 1992; Brown, 1997). But, nowadays, market oriented production has emerged as a key factor that is driving the intensification in land-use in the densely populated urban fringes in Nepal (Brown and Shrestha, 2000). While subsistence farming is characterized by the integration of livestock, forestry with agriculture, traditional mode of production and cultivation in the marginal hills, intensification is characterized by double or triple crop rotations, increased vegetable production, extreme market orientation and unsustainable exploitation of the farmland (Bhatta, 2010).

Farming differentiation within the rural-urban interface of the Middle Mountains of Nepal are mainly due to topographical variation, accessibility, technological penetration and external influence, growing affluence and market demand, all of which have different impacts on different agro-ecological belts within the interface (Bhatta, 2010). Locations of the farm household have made ample socio-economic and spatial differentiation (Bhatta et al., 2009a) which becomes pronounced when farms nearby capital centre are compared with those located farther (KC, 2005). Most of the spatial differentiations are related to road access (Brown, 2003). 
Households with poor road access, for instance, have larger holdings, lower productivity and are much more reliant on subsistence agriculture. Biophysical factors such as variations in the weather, landforms, topography, soil types and resource availability also affect the rural-urban growth pattern (Verbung et al., 2004). In addition, socio-economic factors such as social structure, family composition and needs, economic opportunities, technological availability, cultural needs, demography and political systems also affect the land use change (Briassoulis, 2000), leading to the adoption of different farming practices.

Farmers in the Middle Mountains of Nepal face several challenges: variations in the biophysical situations such as high degree of slope, altitude and accessibility; weather variability, differential rates of soil erosion, a fragile landscape and poor socio-economic base of the farm families and rapid growth in population. Farmers are frequently confronted with making decision on what crops to plant, which crop combinations to apply, which farming components to integrate and at what composition and which farming practice is to adopt and keep it going. These decisions are to be made tactfully considering the knowledge and experience of the farmers along with those factors mentioned above. It is, therefore, important to distinguish the impacting factors involved in farming differentiation. This is done using analytic hierarchy process (AHP) modeling.

The AHP, a flexible method that assigns weight to various factors in a hierarchical structure (Eagan and Weinberg, 1999), is fundamentally a way to quantify the significance of the factors using pair-wise comparisons (Whitaker, 2007). The AHP has proven useful applications in decision making in varieties of the areas (Palcic and Lalic, 2009) involving several factor comparisons. Kauko (2004) argues that most of the classical multi-attribute modeling techniques are based on the assumption of utility functions. However, the AHP is based on the assumption that quantification of a factor without comparing it in a pair doesn't capture better picture. Therefore, the relevant dominance of one attribute over another can be measured by a pair-wise comparison of preferences, systematically made on each level of a hierarchy of factors (Banai-Kashani, 1990; Ramanathan and Ganesh, 1994; Kumar et al., 2009).

Modeling factors that shape up the land use change or the predominance of a particular farming is a challenging job as various factors play different roles at different scales in a particular location (Thapa and Murayama, 2010). Many of such factors are intertwined and hence they may have high degree of relation between them (Bray et al., 2004; Zang and Huang, 2006). Thus, AHP serves the purpose of comparison and finds the important impacting factors of different farming practices. Present investigation employs AHP to understand the determinants of farming differentiation in the rural-urban interface of the Kathmandu Valley, which essentially is a highly variable and rapidly changing farming area with a diversity of farming resources.

\section{The rationale of selecting rural-urban interface of Kathmandu Valley}

The rural-urban interface of the Lalitpur and Bhaktapur districts, which are two of the three districts within the densely populated Kathmandu Valley, in the Middle Mountains of Nepal was selected (Figure 1) considering the following facts.

This area historically has been dominated by the farming activities. The soil fertility of the Valley is better due to a unique soil formation process occurred in that part of the country while rural farmlands are characterized by fragility, marginality and inaccessibility with a high rate of soil erosion.

$>$ Variation in topography, slope and aspect and resource availability are features of the rural-urban interface of the Kathmandu Valley and its adjoining areas. These variations produce a diversity of farming practices.

The selected areas represent a unique rural-urban interface in Nepal as many villages in the districts are not too far from the urban core but have a rural flavor to them. Also many locations have urban concentration with all fundamental amenities accompanied by a decent standard of living (Thapa et al., 2008).

Peri-urban farmers of these districts pursue intensive vegetable and niche market-based organic vegetable production. This area supplies a large volume of vegetables to meet the demand of the urbanites in the Kathmandu Valley. Close to $23 \%$ of the vegetables consumed in the Kathmandu are produced by the farmers in urban and peri-urban fringes of the Kathmandu Valley and its adjoining areas. This figure can be improved further to $76 \%$ by improving the existing farming practices and constructing a road network from the peri-urban to the urban area (Pradhan and Parera, 2005).

\section{Methodology used}

\subsection{Description of the study area}

Urban fringe of the study area is located in the Kathmandu Valley mostly in the Bhaktapur district while peri-urban fringe is located in the hilly part of Lalitpur district. The Valley lies between the latitudes $27^{\circ} 32^{\prime} 13^{\prime}$ " 
and $27^{\circ} 49^{\prime} 10^{\prime \prime}$ north and longitudes $85^{\circ} 11^{\prime} 31^{\prime \prime}$ and $85^{\circ} 31^{\prime} 38^{\prime \prime}$ east and is located at a mean elevation of about 1,300 meters above sea level- the highest altitudes are 2,166 m in Bhaktapur, 2,732 $\mathrm{m}$ in Kathmandu, and 2,831 $\mathrm{m}$ in Lalitpur. The Valley comprises of three districts viz., Kathmandu, Lalitpur and Bhaktapur (Figure 1d), together which cover an area of $899 \mathrm{sq} . \mathrm{km}$., whereas the area of the Valley as a whole is $665 \mathrm{sq} . \mathrm{km}$. (Pant and Dongol, 2009). The Valley encloses the entire area of Bhaktapur, $85 \%$ of Kathmandu and $50 \%$ of Lalitpur. With more than 1.5 million inhabitants, the Valley, as a capital city, is also an important urban concentration in Nepal (Pant and Dongol, 2009).

Figure $1 \mathrm{~b}$ shows that the study area is composed of altitudinal gradient ranging from 900 to 2500 meters above sea level with a median range of 1000 to 1500 meters. While a sizeable portion of the area possesses elevation that ranges from 1500 to 1800 meter above sea level, area with less than 1000 meters of elevation is negligible. The degree of slope prepared through digital elevation model in ArcView 3.3 shows differential gradient within the study area (Figure 1c). A sizeable part of the study area is flat or nearly flat (0 to $5 \%)$ while a large chunk of area has steep slope $(>30 \%)$. Rural hills, in general, have relatively higher slope than that of the urban and peri-urban areas. Slope along with the fragile landscape leads to the severe soil erosion in the hill farming systems throughout the country (Brown and Shrestha, 2000). The great variations in the elevation, slope and aspect within the short transect of study area is the fertile source of weather differentiation and adaptability of different plant species leading to the differentiation in farming systems and local livelihoods (Bhatta, 2010). For instance, the lowland lower elevations are suitable for rice-wheat cropping pattern while the higher elevations are suitable for maize-based cropping (Rajbhandari and Bhatta, 2008). Moreover, development of infrastructures also depends on the elevation. The flatlands are supposed to be fertile and it would be fairly convenient for the government to supply irrigation and other infrastructures in these areas.

The urban and peri-urban fringes of the Kathmandu Valley and its adjoining areas have experienced unprecedented land subdivision and building construction boom over the past several years. There has been an exceptional growth of human settlement and increase in the value of land and housing (Pradhan and Parera, 2005). Farming in the Valley is characterized by a small parcel of land, highly fertile soils and market-oriented vegetables production. However, the amount of land available for urban and peri-urban agriculture is continuing to shrink while the demand for food in the cities is rising due to large-scale migration from rural areas. This is not only creating environmental problems, but also threatening the agro-ecological balance.

\subsection{Delineation of homogeneous farming zones}

A reconnaissance survey of the study area was made in advance of the farming zone delineation. Key informant interviews coupled with informal discussions and observations were accomplished for locating a more or less homogeneous farming zone. With this process, a total of three distinct zones were delineated (Figure 1e) viz., rural area with subsistence farming (hereafter called subsistence zone), market oriented farming (hereafter called commercial inorganic zone) and niche market-based organic vegetable farming (hereafter called smallholder organic zone). Four key criteria were used for delineating homogeneous farming zones.

The first criterion was the degree of market orientation. It distinguished the farmers who were mainly subsistence producers with a traditional mode of production and almost no market orientation. They were followed by those who were commercially motivated and producing crops mainly vegetables using high amount of agro-chemicals. The third group produced organic vegetables in small parcel of the land for niche markets in the urban cores.

The second criterion of classification was the prominence of cropping pattern. On the basis of this, subsistence farming was dominated by maize-based cropping pattern while both commercial inorganic and smallholder organic farming were dominated by rice-based cropping pattern. There was also a differential agro-biodiversity in situ in different farming zones. For instance, hilly subsistence farming showed higher number of crops in the field (Figure 2) while only few crops could be seen in the lowland inorganic farming area (Figure 3) and several vegetable species were there in the smallholder organic farming zone (Figure 4).

The third was the spatial criterion such as slope, altitude and infrastructure availability (road, market, and electricity and extension services). With this, subsistence farming was prevalent in the high altitude, remote areas with sloppy terrains, far from market and infrastructures (Figure 2) while commercial inorganic farming was prevalent in low lying, Valley bottom with irrigation and infrastructure facilities (Figure 3). Smallholder organic farming was practiced in the middle altitude nearby market and information centre (Figure 4).

The fourth criterion embraced the practice of farming itself. Subsistence farmers followed a traditional farming pattern sometimes referred as 'organic by default'. The integration of forest and livestock with agriculture is common feature of such farming. On the other hand, commercial inorganic farming experienced the heavy use of 
agro-chemicals while production was done organically in the smallholder organic zone. Many farms in the smallholder organic zone had a two-tier production system: organic for income-generating crops like vegetables; conventional for subsistence production.

\subsection{Sampling technique}

The study was based on micro-survey of the farm households that were selected using spatial and random sampling procedures. Through spatial sampling, a total of 60 and 35 farm households were selected respectively from the subsistence and commercial inorganic farming zones while 35 farm households from the smallholder organic farming zone were selected by employing simple random sampling method. Spatial sampling was adopted in two zones because information on the number of households that had settled down was not available and the settlement was scattered in a wide area. The spatial sampling method is based on the concept of spatial dependency which relies on the principle of proximity of locations to one another. Closer locations are expected to have more similar values than those farther away (Tobler, 1970). The selection of this method is based on the principle that all households settled down in the study area were surveyed. For implementing spatial sampling, a buffer of $4.8 \mathrm{~cm}$ diameter in the paper which is equivalent to $1.2 \mathrm{~km}$ in the space was drawn in ArcVeiw 3.2 so as to cover the entire area under investigation excluding forest areas. In this way, a buffer with three eccentric rings uniformly spaced inside had a total area of $1.13 \mathrm{sq} . \mathrm{km}$. in the space. An attempt was made to select centrally located household from the buffer. However, due to some constraints such as farmer's reluctance in providing data and very negligible land holding, some of the sampled households lie slightly far from the central point. Ipso facto, all of the households fall inside the buffers and only one household was selected per buffer. Finally 100 buffers were made out of which 95 were selected.

\subsection{Crucial factors of farming differentiation}

Farming practices are shaped by several factors which depend on the socio-economic, bio-physical and demographic structure of the farm families, infrastructure availability, market demand and needs, objectives and motivations of the farm families, to name a few. The urban area has a different farming orientation than in the rural because of improved inputs and infrastructure availability. In general, the urban growth that causes land use changes is a result of the complex interaction between behavioral and structural factors associated with the demand, technological penetration and input availability (Thapa and Murayama, 2010). There are no universal factors that describe a particular farming practice. Nevertheless, certain factors play a dominating role over others under varied agro-ecological and bio-physical situations. Although a set of similar factors have been noticed in several studies, the degree to which they contribute to the landscape change differs (Verburg et al., 2004; Zang and Huang, 2006).

Several changes have been going on in the rural-urban interfaces of Nepal and this is quite pronounced in the key interfaces such as the Kathmandu Valley and its surrounding environment. These changes are basically owing to the centric nature of development. The changes in farming are attributed to by the increasing food demands in the urban cores, resource availability and farmers' motivations along with socio-economic characters of the farm family and the biophysical set up of the household. This study explores the set of factors that govern such farming practices followed by their importance in order using AHP. Over a dozen of factors had been noted down through informal discussions with the key informants and were subjected to pre-testing in each farming zone. Finally, a total of seven factors were selected to be considered under the AHP framework. These factors were first categorized into four criteria levels viz., biophysical, enterprise, market and resources. They were then divided into seven sub-criteria called factors of farming differentiation. These factors were subjected to test through AHP against each farming zone. The detail account of these factors is depicted in Table 1.

\subsection{AHP and matrix construction}

The Analytic Hierarchy Process (AHP) is a multi-criteria decision support tool that aims at solving complex decision problems (Triantaphyllou and Mann, 1995) and was originally developed by Prof. Thomas L. Saaty (Saaty, 1980, 1986). The essential feature of AHP is that it converts individual preferences into ratio scale weights thereby providing the avenue for effective comparison and ranking of the decision factors. AHP has been used in diverse areas ranging from key factors of urbanization (Thapa and Murayama, 2010), fire risk analysis (Long et al., 2009), engineering decision making (Triantaphyllou and Mann, 1995), project selection, evaluation and management (Palcic and Lalic, 2009; Al-Harbi, 2001; Al-Khalil, 2002), vendor selection (Kumar et al., 2009), housing sector (Chauhan et al., 2008; Ball and Srinivasan, 1994), banking (Arbel and Orgler, 1998) to marketing (Wind and Saaty, 1980).

The key attributions of AHP are the hierarchical structure of complexity, pair-wise comparisons, redundant judgments, an eigenvector method for deriving weights and consistency considerations (Kumar et al., 2009). 
Like many other methods, AHP allows decision makers to create a model of a complex problem with the goal at the top and criteria, sub-criteria (factors) and alternatives at levels in drop-down manner (Saaty, 2008). The general framework of AHP used in the study is depicted in the Figure 5.

As seven criteria were selected for finding their influence on the predominance of a particular farm practice, the dimension of the matrix, therefore, is $7 \times 7$. It is because one column and one row correspond to each factor and there were 21 pair-wise comparisons using the formula $\{\mathrm{n} *(\mathrm{n}-1) / 2\}$. If this matrix is denoted as $A=\left\{a_{i j}\right\}$ where $a_{i j}$ is the element of $i^{\text {th }}$ row and $j^{\text {th }}$ column of the matrix, all it's entries are obtained by inscribing the relative importance of each criterion over another with respect to the goal. Pair-wise comparison can be performed by assigning an integer ranging from 1 to 9 or the reciprocal of such an integer to each cell of the matrix (Crowe et al., 1998; Hafeez et al., 2002; Saaty, 2008) to measure the relative importance of the factors that characterize the cell (Table 2). To fill the lower triangular matrix, the reciprocal values of the upper diagonal are used as, $a_{j i}=$ $1 / a_{i j}$ where $a_{i j}>0$ (Table 3 ).

In the AHP matrix, the cells along the diagonal are given the value of 1 (Table 3) so that the row factor compared to the same column factor receives a unit value. The cell representing two different factors in row and column with equal contribution or influence also gets a unit value. The user, however, has to realize that this choice is itself a statement of relative value (Eagan and Weinberg, 1999).

The AHP approach assumes that each of the factors under assessment is independent. It allows some small inconsistency in the judgment because human responses are not always consistent. In practice $100 \%$ consistency is difficult to achieve, but the method can still be applied when there is some degree of interdependence. For calculating the index of inconsistency, AHP uses consistency ratio (CR) (Saaty, 1986). Values of inconsistency index lower than $10 \%$ are acceptable (Saaty, 1986), particularly if matrix is 4 by 4 or above (Cheng and Li, 2001). In certain cases, although higher value of inconsistency index requires re-evaluation of pair-wise comparisons (Kumar et al., 2009), decisions obtained in that kind of situation could also be taken as 'the best alternative'. Consistency index (CI) is calculated as:

$$
C I=\frac{\lambda_{\max }-n}{n-1}
$$

The CI of a randomly generated reciprocal matrix is called random index (RI). An average RI for the matrices of order 1-15 can be found in Saaty (1980). The CR can hence be calculated as the ratio of CI to RI (CR = CI/RI).

AHP involves several steps starting from factor definition and data collection to the checking of precision (Figure 6). The first three steps embrace the data collection followed by factor valuation, in which the weight associated to each factor under investigation are established, and finally the test of the inconsistency is done.

\section{Results and discussion}

\subsection{Socio-demographic description of the sample}

One half of the respondents interviewed were illiterate in subsistence farming while it was $31 \%$ and $40 \%$ respectively in commercial inorganic and smallholder organic farming zones (Table 4). This depicts the lower level of literacy in the rural areas compared to the urban and peri-urban areas. This is further buttressed by the substantially lower percentage of respondents with higher level of education in the subsistence farming zone while a sizeable percentage of respondents with higher level of education were found in the urban farming zones. The people living in the rural areas have lesser accessibility to the public transportation, education and other amenities which are fundamental for development (Thapa and Murayama, 2010). Most of the respondents interviewed were males except in the smallholder organic zone. This reflects the patriarchal family structure in which the females are largely responsible for household chores and farm activities (Brown, 2003). Females are generally busy in their day to day work and as such they don't have time to give information. Even if they have time, they are hesitant. However, the tendency of females to restrict in the household chores is weakening in the urban areas. In the case where males were not available at the time of taking data, females were requested and referred to. In smallholder organic zone, most of the females were referred to. This is because this zone is near the urban market and most of the males go to the urban areas for work or for refreshment and females are mostly the ones found in the homestead or in the farm.

Farming was the main profession and a key source of livelihood for the farmers in the subsistence zone. Although farming still contributes to family livelihoods in the remaining zones, the share on family income through off-farm work such as government jobs, own enterprises, jobs in the private sector and I/NGOs account more in the more accessible areas. Because of the centralized development and governance system, industries 
and government agencies are confined to the urban areas (Thapa et al., 2008). This has in turn created various types of jobs absorbing significantly large portion of the population (Thapa and Murayama, 2010). Therefore, farming in urban area is not concerning due attention. This is leading to a rapid land use change from farming to non-farm use, especially land business for settlement.

Family size and total land available per family were significantly higher in the subsistence zone as compared to the others. The dependency ratio, although higher in the subsistence zone, was on a par with other zones. The higher family size in the subsistence zone is basically due to the family's need for more farm labor, lack of education and lack of knowledge and services of family planning (CBS, 2005). The family size and dependency ratio at the national level are higher in the rural areas than in the urban areas (CBS, 2007). Since the soil fertility is very low and production from each crop is far from satisfactory, a farm family owns more land in the rural hill to meet at least its subsistence needs. The land holding was substantially lower in the urban areas. It is basically due to the rapid fragmentation of land once a family separates and the growing land business which gives huge economic benefit to the farmers even when selling a small piece of their land. The national data also indicates that the average land holding is lower in the urban areas (CBS, 2003).

\subsection{Results of AHP}

Figure 7 shows the weight of the impacting factors of farming differentiation in different agro-ecological zones and is expressed in terms of priority vector. The biophysical factor as expressed in terms of inaccessibility of the roads and transportation, basic services, extension and input-output markets was found to have a major impact on the continuation of subsistence farming. Subsistence farming- which has a purely rural flavor- is slightly far from the urban fringe, some 25-30 km away from the Kathmandu Metropolis. This zone lacks infrastructures which are fundamental for development. Inaccessibility, which keeps the farming community away from new technologies and markets, was given extremely higher weight as compared to other factors included in the AHP framework. Comparing the impact of physical conditions, it has strong influence in the rural areas than in the others (Thapa and Murayama, 2010). Followed by inaccessibility was the use of the local resources and agro-ecological considerations. The rural areas are enriched with resources such as forest, livestock and human. The integration of forest and livestock with agriculture is more or less a default practice in the rural hills. Because of the lack of mechanization and a fragile landscape, farming in the rural area depends solely on the use of human resources. Harvesting higher yields got a weaker priority in this zone. Similar to this was the higher price, better quality and higher market demand of the products.

Most of the factors under investigation were closely intertwined in commercial inorganic farming. It is because this zone lies nearby the urban core which is densely inhabited with a huge daily demand of perishable vegetables. Because of the higher accessibility coupled with dense population leading to the higher market demand, several factors had similar impact in farming development. Nevertheless, the relative impact of different factors differed. The farmers' immediate objective of harvesting higher yield was the main growth promoter of commercial farming. This was followed by accessibility leading to an efficient input-output marketing. Along with this was the higher demand of the farm produce by the urbanites. Farmers address this huge demand through intensive production with imprudent use of agro-chemicals with a hope to catch higher yield within a short span of time (Bhatta and Doppler, 2009). Higher price and better quality of the products had weaker impact in this zone. It is because farmers don't have to incur much loss during marketing of the products and the existing market price too is also reasonable. Furthermore, farmers also compromise quality with higher yield because the interest is to produce more.

The farmers' motivation towards agro-ecological consideration of the farming was the main impacting factor of smallholder organic production. This was followed by the higher quality production of the vegetables. The basic motivation of the organic producer was not income but rather their ecological sensitivity and the resources available to them. This is further buttressed by the farmers' initiation to adopt organic farming. The government doesn't provide any economic incentives to the organic producers. Organic market is poorly developed with the lack of market information and consumer awareness (Bhatta et al., 2009b). Most of the organic farmers had followed inorganic practices in the past and experienced a sharp decline in the yield along with the degradation of soil and environment (Bhatta, 2010). This realization turned them towards organic farming practice. Farmers also believed that organic practice produces quality products. That's why this factor came in the second priority listing. The accessibility factor too received a strong weight. This zone is quite near to the Valley centre where a large chunk of organic consumers inhabit and there are few supermarkets selling organic products and restaurants offering organic foods. Therefore, farmers don't have to incur huge loss in selling organic products and the selling price is also reasonable. Higher demands of the farm produce, especially in the niche organic market and use of local resources also got strong weights. Higher yield received the least priority weighting. This 
is because the farmers' motivation is to harvest better quality vegetables that would get a better price, at least in the niche market. Yield motivation and agro-ecological considerations were two contrasting growth promoters of commercial inorganic and smallholder organic zones although both of the farming zones despite the fact that both farming zones lie nearby the capital and have a similar level of development.

Higher consistency was associated with commercial inorganic farming zone $(\mathrm{CR} \approx 7 \%)$ while it was slightly lower for the subsistence farming $(\mathrm{CR} \approx 9 \%)$ and smallholder organic farming ( $\mathrm{CR} \approx 10 \%)$. The relatively elevated CR in smallholder organic zone is basically due to the two-tier production system of the farmers. That is, vegetables were produced organically and the food crops inorganically. Some farmers in this zone even followed inorganic practice for vegetable production. Similarly, within this zone, some farmers were large holders of organic farm and hence the factor judgments of smallholder and large holder farmers differed. In the same way, the subsistence farming zone covered a wider area with scattered settlements and differential production practices. Those living nearby the road buffers were adopting market-oriented inorganic farming while those farther away were following the same traditional form thereby reflecting some inconsistency in gauging the factors. Ipso facto, consistency percentages of all zones lie within the given perimeter, that is, $10 \%$ (Saaty, 1980).

Figure 8 presents the ranking of the factors in each farming zone $\left(1^{\text {st }}\right.$ order is the highest impact and $7^{\text {th }}$ order is the lowest impact). The aspiration to get a higher yield was the foremost factor of motivation followed in order by accessibility, high market demand of the agro-products particularly vegetables and reasonable price of the products in commercial inorganic farming. The physical inaccessibility and remoteness followed in order by availability and use of local resources including family labour in the farm activities, agro-ecological consideration and yield were the key factors in the subsistence farming. Strong emphasis towards agro-ecology of the farming practice followed in order by quality production, accessibility and higher demand in the niche market for organic produce were some of the motivating factors towards organic production. Many of the preference ranks were similar in commercial inorganic and smallholder organic farming (accessibility, market price of the products and local resource use) while some of the ranks were contrastingly different (yield and agro-ecological considerations, for instance). In contrast, none of the rank at the subsistence zone coincided with the other zones.

Similar factors of growth in the urban, fringe and rural areas are also documented by Thapa and Murayama (2010). Farming differentiation is typically driven by a variety of forces that relate to one another based on different spatial and temporal settings. Antrop (2005) highlighted accessibility, urbanization and economic opportunities as important factors while Verbung et al. (2004) identified biophysical characteristics, socio-economic conditions, accessibility and spatial policies as the major growth promoters of landscape change and hence, farming differentiation. AHP gives the ranking and preferences of the farmers towards an umbrella of factors thereby finding the crucial factors that shape the adoption of a particular farming practice.

\section{Conclusion}

The use of AHP in production system is considered a convenient approach to diagnose important factors and the farmers' choice variables. This would give more opportunities to explain and elaborate preference data into ratio scale. The application of AHP in finding the dominant factors that influence the adoption of a particular farming practice shows that rural inaccessibility is most influential factor of subsistence farming while farmers' objective of harvesting higher yield is the main growth promoter of inorganic farming and agro-ecological consideration is the main motivation towards smallholder organic production. Commercial inorganic and smallholder organic farming zones are near the capital city and as such several factors are common. However, impact factors towards farming differentiation are uncommon. Agro-ecological considerations, good quality and the use of local resources are the least impacting factor in the commercial inorganic zone whilst they are the most impacting factor in the smallholder organic zone.

The quantification of the impacting factors of farming differentiation is an important piece of information that will contribute to the modeling farming practices in the rural-urban interface. This empirical quantification of the factors through AHP is an important reference for the planning of agriculture development in the rapidly growing rural-urban interface of the densely populated cities in Nepal and such similar domain in other developing countries.

\section{Acknowledgement}

Financial support provided by the German Academic Exchange Service (DAAD) is gratefully acknowledged. We also extend our vote of thanks to the anonymous reviewers for making this paper more contextual. 


\section{References}

Al-Harbi, K.M. (2001). Application of the AHP in project management. International Journal of Project Management, 19, 19-27.

Al-Khali, M.I. (2002). Selecting the appropriate project delivery method using AHP. International Journal of Project Management, 20, 469-474.

Antrop, M. (2005). Why landscapes of the past are important for the future. Landscape and Urban Planning, 70, 21-34.

Arbel, A. \& Orgler, Y.E. (1998). An application of AHP to bank strategic planning, the mergers and acquisitions process. European Journal of Operational Research, 48, 47-37.

Ball, J. \& Srinivasan, V.C. (1994). Using the analytic hierarchy process in house selection. The Journal of Real Estate Finance and Economics, 9, 69-85.

Banai-Kashani, A.R. (1990). Dealing with uncertainty and fuzziness in development planning, a simulation of high-technology industrial location decision making by the analytic hierarchy process. Environment and Planning, 22, 1183-1203.

Bhatta G.D., Doppler, W. \& KC, K.B. (2009a). Spatial differentiation in farming practices and their impact on rural livelihood: a case from hills of Nepal. In: E. Tielkes (Ed) Book of Abstract, International Research on Food Security, Natural Resource Management and Rural Development, Hamburg, Germany.

Bhatta, G.D. \& Doppler, W. (2009). Application of conjoint modeling in Nepalese vegetable market. Nepalese Journal of Agricultural Sciences, 7, 1-12.

Bhatta, G.D. (2010). Bio-farming and marketing in Nepal: through producer, consumer, trader and spatial perspectives. In: W. Doppler \& K.B. KC (Eds) Farming and Rural Systems Economics and Biodiversity in the Tropics, Margraf Publishers, Germany.

Bhatta, G.D., Doppler, W. \& KC, K.B. (2009b). Potential of organic agriculture in Nepal. Journal of Agriculture and Environment, 10, 1-11.

Bray, D.B., Ellis, E.A., Armijo-Canto, N. \& Beck, C.T. (2004). The institutional drivers of sustainable landscapes: a case study of the 'Mayan Zone' in Quintana Roo, Mexico. Land Use Policy, 21, 333-346.

Briassoulis, H. (2000). Analysis of land use change, theoretical and modeling approaches. In: W.R. Jackson (Ed.), The web-book of regional science, USA. Regional Research Institute, West Virginia University.

Brown, S. \& Shrestha, B. (2000). Market driven land use dynamics in the middle mountains of Nepal. Journal of Environment Management, 59, 217-225.

Brown, S. (1997). Soil fertility, nutrient dynamics and socioeconomic interactions in the middle mountains of Nepal. Ph. D. dissertation submitted to Interdisciplinary Studies in Resource Management Science, University of British Columbia, Canada.

Brown, S. (2003). Spatial analysis of socio-economic issues, gender and GIS in Nepal. Mountain Research and Development, 23, 338-344.

Carson, B. (1992). The land, the farmer and the future: a soil fertility management strategy for Nepal. ICIMOD Occasional Paper No. 21, Kathmandu, Nepal.

CBS. (2003). Population monograph, 2003. His Majesty's Government, Central Bureau of Statistics, Kathmandu, Nepal.

CBS. (2005). Nepalese living standard survey 2003/04, Statistical Report II. Central Bureau of Statistics, Government of Nepal.

CBS. (2007). Statistical year book of Nepal 2007. His Majesty's Government, Central Bureau of Statistics, Kathmandu, Nepal.

Chauhan, K.A., Shah, N.C. \& Rao, R.V. (2008). The analytic hierarchy process as a decision-support system in the housing sector: a case study. World Applied Science Journal, 3, 609-613.

Cheng, E.W.L. \& Li, H. (2001). Information priority-setting for better resource allocation using analytic hierarchy process (AHP). Information Management and Computer Security, 9, 61-70.

Crowe, T.J., Noble, J.S. \& Machimada, J.S. (1998). Multi-attribute analysis of ISO 9000 registration using AHP. International Journal of Quality and Reliability Management, 15, $205-222$. 
Eagan, P. \& Weinberg, L. (1999). Application of analytic hierarchy process techniques to streamlined life-cycle analysis of two anodizing processes. Environment Science and Technology, 33, 1495-1500.

Hafeez, K., Zhang, Y. \& Malak, N. (2002). Determining key capabilities of a firm using analytical hierarchy process. International Journal of Production Economics, 76, 39-51.

Jodha, N.S. (1995). Nepal's middle mountains. In: Kasperson, J.X., R.E. Karperson \& B.L. Turner (Eds) The regions at risk, comparison of threatened environments. United Nations University Press, Tokyo, Japan.

Kauko, T. (2004). Sign value, totophilia, and the locational component in property prices. Environment and Planning, 36, 859-878.

KC, K.B. (2005). Combining socio-economic and spatial methodologies in rural resources and livelihood development: a case from Mountains of Nepal. Wekersheim, Margraf Verlag, Germany.

Kumar, S., Parashar, N. \& Haleem, A. (2009). Analytical hierarchy process applied to vendor selection problem: Smallscale, medium scale and large scale industries. Business Intelligence Journal, 2:355-362.

Long, S., Zhang, R.F., Xie, Q.Y. \& Fu, L.H. (2009). Improving analytical hierarchy applied to fire risk analysis of public building. Chinese Science Bulletin, 54, 1442-1450.

Palcic, I. \& Lalic, B. (2009). Analytical hierarchical process as a tool for selecting and evaluating projects. International Journal of Simulation Modeling, 8, 16-26.

Pant, P.R. \& Dongol, D. (2009). Kathmandu Valley profile- briefing paper. Kathmandu Metropolitan City, Nepal.

Pradhan, P. \& Perera, R. (2005). Urban growth and its impact on the livelihoods of Kathmandu Valley, Nepal. Urban Management Program for Asia and the Pacific, Urban Resource Network for Asia and Pacific.

Pradhan, P.K. (2003). Rainfall induced natural hazards in the Middle Mountains of Nepal. Geophysical Research Abstracts, 5, 01041.

Rajbhandari, B.P. \& Bhatta, G.D. (2008). Food crops- agro-ecology and modern agro-techniques. Himalayan College of Agricultural Sciences and Technology, Kathmandu, Nepal.

Ramanathan, R. \& Ganesh, L.S. (1994). Group preferences aggregation method employed in AHP: An evaluation and an intrinsic process for deriving members' weightings. European Journal of Operational Research, 79, 249-265.

Saaty, T.L. (1980). The analytic hierarchy process. Pittsburgh, McGraw-Hill, Inc, Reprinted by RWS Publications.

Saaty, T.L. (1986). Axiomatic foundation of the analytic hierarchy process. Management Science, 32, 841-855.

Saaty, T.L. (2008). Decision making with the analytic hierarchy process. International Journal of Services Sciences, 1, 83-98.

Thapa, R.B. \& Murayama, Y. (2010). Drivers of urban growth in the Kathmandu Valley, Nepal: Examining the efficacy of the analytical hierarchy process. Applied Geography, 30, 70-83.

Thapa, R.B., Murayama, Y. \& Bajimaya, M. (2008). Kathmandu. Cities, 25, 45-57.

Tobler, W.R. (1970). A computer movie simulating urban growth in the Detroit Region. Economic Geography, 234-240.

Triantaphyllou, E. \& Mann, S.H. (1995). Using the analytical hierarchy process for decision making in engineering applications: some challenges. International Journal of Industrial Engineering, 2, 35-44.

Verbung, P.H., van Eck Ritsema, J., De Nijs, T., Schot, P. \& Dijst, M. (2004). Determinants of land-use change patterns in the Netherlands. Environment and Planning, 31, 125-150.

Whitaker, R. (2007). Validation examples of the analytic hierarchy process and analytic network process. Mathematical and Computer Modeling, 46, 840-859.

Wind, Y. \& Saaty, T.L. (1980). Marketing applications of the analytical hierarchy process. Management Science, 26, 641-658.

Zang, S. \& Huang, X. (2006). An aggregated multivariate regression land-use model and its application to land-use change processes in the Daqing region (Northeast China). Ecological Modeling, 193,503-516. 
Table 1. Impacting factors included in the AHP with their definition

\begin{tabular}{|c|c|c|}
\hline No & Factors & Definition \\
\hline 1 & Accessibility & $\begin{array}{l}\text { Relation to the market, availability of the roads and means of transportation, access } \\
\text { to the extension services and other amenities }\end{array}$ \\
\hline 2 & Yield & Production per hectare per crop \\
\hline 3 & Quality & $\begin{array}{l}\text { Physical appearance of the crop, internal composition which is not gauged } \\
\text { quantitatively but supposed to be good for organically grown produce as compared } \\
\text { to those inorganically produced commodities }\end{array}$ \\
\hline 4 & Demand & Amount needed in the city cores which is largely a function of population \\
\hline 5 & Price & Farm gate price of the products particularly vegetables \\
\hline 6 & Agro-ecology & $\begin{array}{l}\text { Situation of the production environment such as better aerial and edaphic } \\
\text { environment, micro-organisms in the soil, health of the farmers, soil conservation } \\
\text { and land quality }\end{array}$ \\
\hline 7 & Resources & $\begin{array}{l}\text { Situation of the farming resources such as human and livestock, forest, } \\
\text { agro-biodiversity, indigenous knowledge, local cultivars }\end{array}$ \\
\hline
\end{tabular}

Table 2. Saaty's scale of pair-wise comparisons

\begin{tabular}{|c|c|c|}
\hline $\begin{array}{l}\text { Intensity of } \\
\text { importance }\end{array}$ & Definition & Explanation \\
\hline 1 & Equal importance & Two factors contribute equally \\
\hline 3 & Weak importance of one over another & Experience and judgment slightly favor \\
\hline 5 & Essential or strong importance & Experience and judgment strongly favor \\
\hline 7 & Demonstrated importance & A factor is strongly favored and its \\
\hline 9 & Absolute importance & The evidence favoring one factor over \\
\hline $2,4,6,8$ & & When compromise is needed \\
\hline $\begin{array}{l}\text { Reciprocals of } \\
\text { above nonzero }\end{array}$ & \multicolumn{2}{|c|}{$\begin{array}{l}\text { If factor } i \text { has one of the above nonzero number assigned to it when compared with factor } \\
j \text {, then } j \text { has the reciprocal value when compared with } i\end{array}$} \\
\hline
\end{tabular}

Source: Wind and Saaty, 1980

Table 3. An illustrative data collection matrix

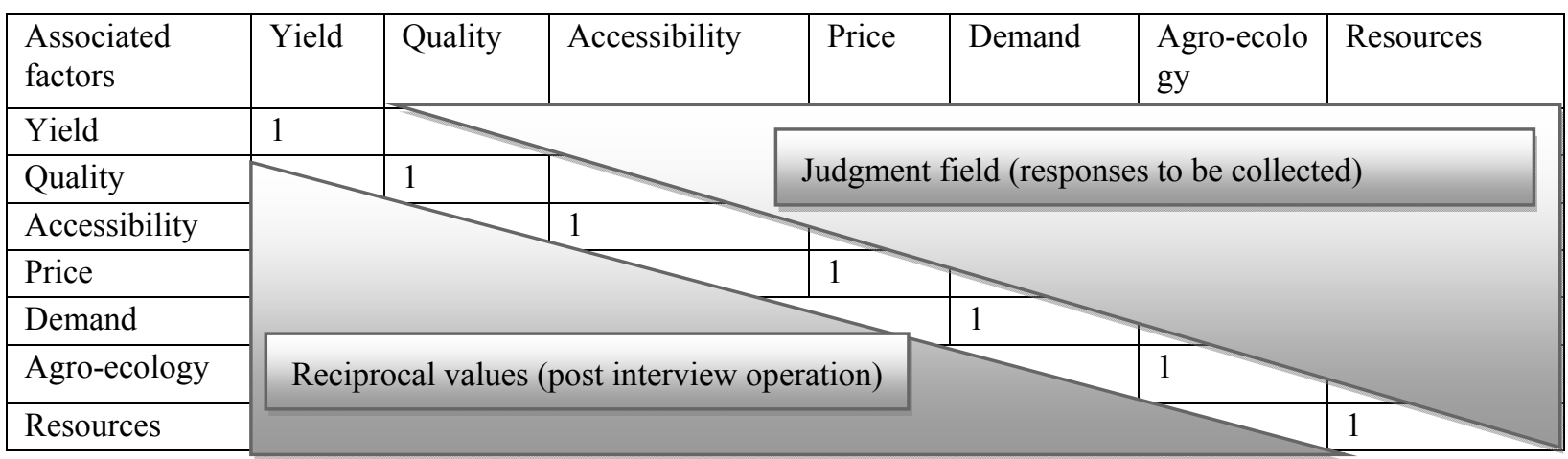

Source: Modified from Wind and Saaty, 1980 
Table 4. Socio-demographic attributes of the respondents in three farming zones

\begin{tabular}{|c|c|c|c|}
\hline Variables & $\begin{array}{l}\text { Subsistence } \\
(\mathrm{n}=60)\end{array}$ & $\begin{array}{l}\text { Commercial inorganic } \\
(\mathrm{n}=35)\end{array}$ & $\begin{array}{l}\text { Smallholder organic } \\
(\mathrm{n}=35)\end{array}$ \\
\hline \multicolumn{4}{|l|}{ Education (\%) } \\
\hline Illiterate & 50 & 31 & 40 \\
\hline Primary & 28 & 23 & 17 \\
\hline Secondary & 17 & 34 & 31 \\
\hline Above secondary ${ }^{\S}$ & 5 & 12 & 12 \\
\hline \multicolumn{4}{|l|}{$\operatorname{Sex}(\%)$} \\
\hline Male & 68.3 & 85.7 & 37.1 \\
\hline Female & 31.7 & 14.3 & 62.9 \\
\hline \multicolumn{4}{|l|}{ Main profession (\%) } \\
\hline Farming & 95 & 60.0 & 54.3 \\
\hline Government job & 5 & 22.9 & 25.7 \\
\hline Job in other sectors ${ }^{\partial}$ & 0 & 17.1 & 20.0 \\
\hline Age (year) & $42.60(14.38)$ & $42.95(16.60)$ & $43.17(11.95)$ \\
\hline Family size & $6.95^{\mathrm{a}}(2.93)$ & $5.45^{\mathrm{b}}(2.11)$ & $5.75^{\mathrm{b}}(2.62)$ \\
\hline Dependency ratio in the family & $0.67(0.53)$ & $0.51(0.42)$ & $0.51(0.49)$ \\
\hline Total land available & $0.90^{\mathrm{a}}(0.98)$ & $0.26^{\mathrm{b}}(0.22)$ & $0.40^{\mathrm{b}}(0.27)$ \\
\hline
\end{tabular}

Figures in the parentheses are standard deviations; Letters in the superscript show the significant difference between groups at 0.05 level of probability according to Mann-Whitney test and values with similar letters are not significant

${ }^{\S}$ Education above $10^{\text {th }}$ grade

${ }^{\circ}$ Involvement in I/NGO, private firm, industries, private schools and colleges, own enterprise etc 


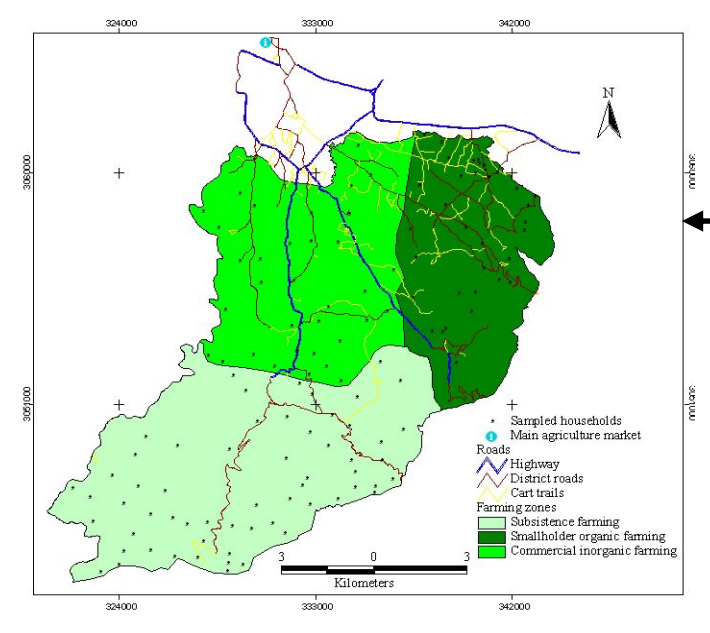

e)
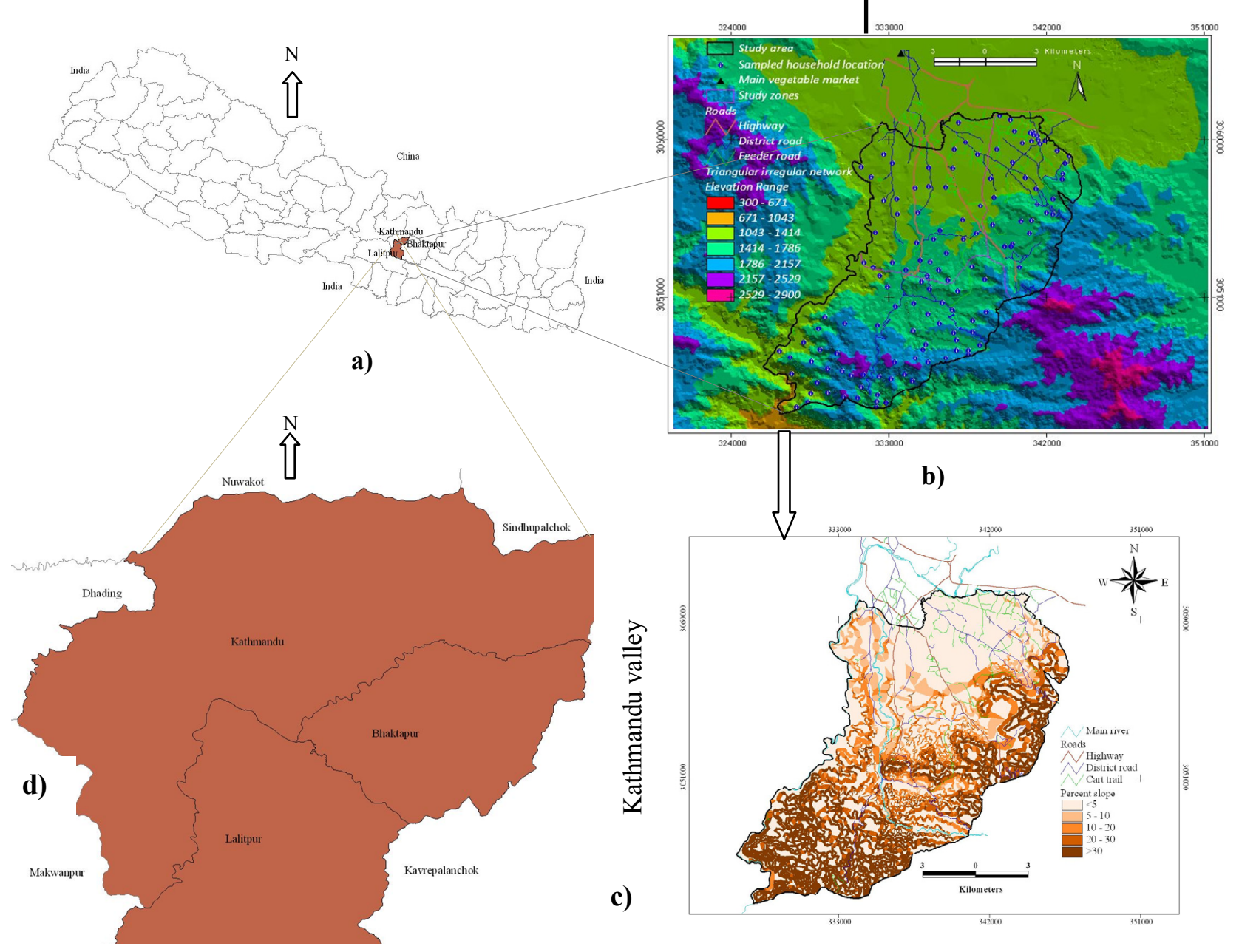

b)

c)

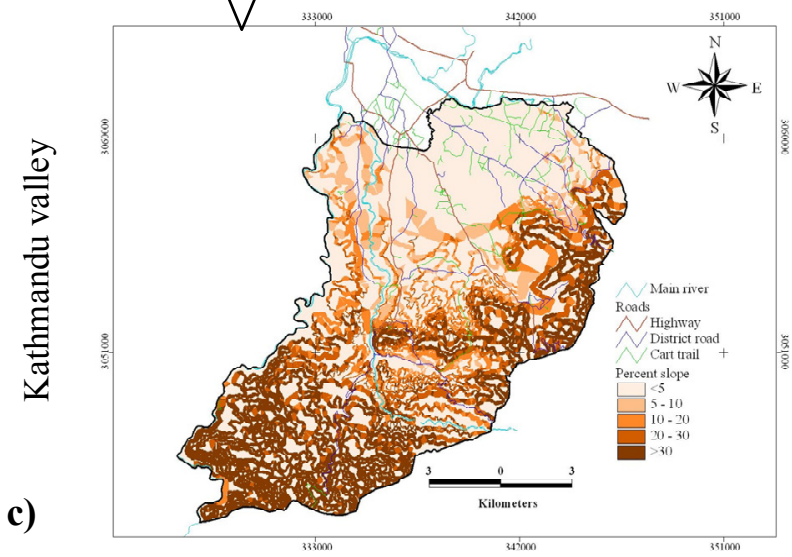

Figure 1. Location of the study area in the map a) Map of Nepal showing study districts b) Study area represented by digital elevation model (elevation expressed in meter above sea level) with other infrastructures c)

Slope (\%) in the study area d) Kathmandu Valley with adjoining districts e) Farming zones showing sampled household 


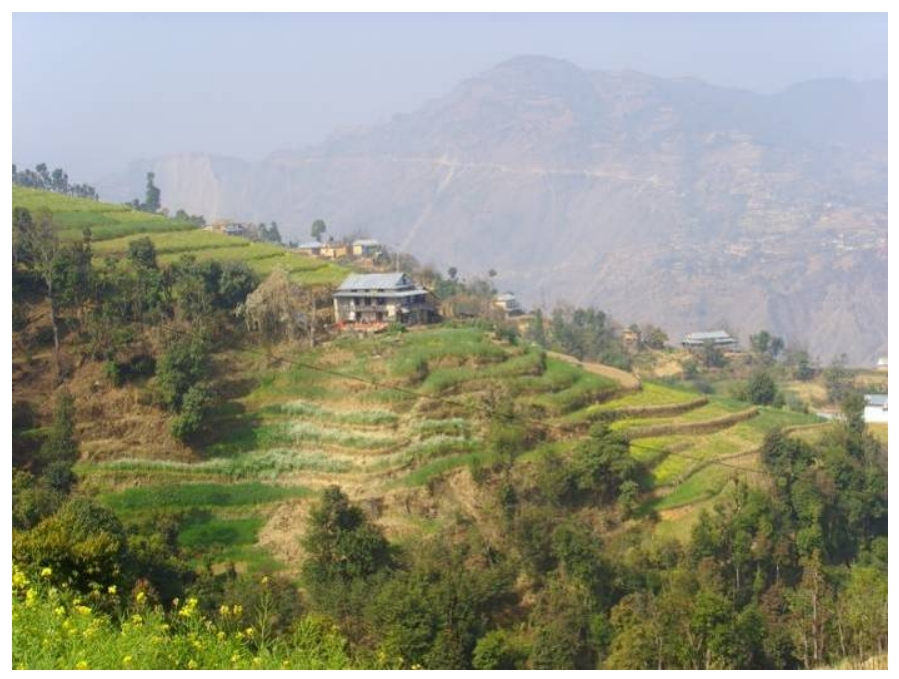

Figure 2. Subsistence farming in the rural area

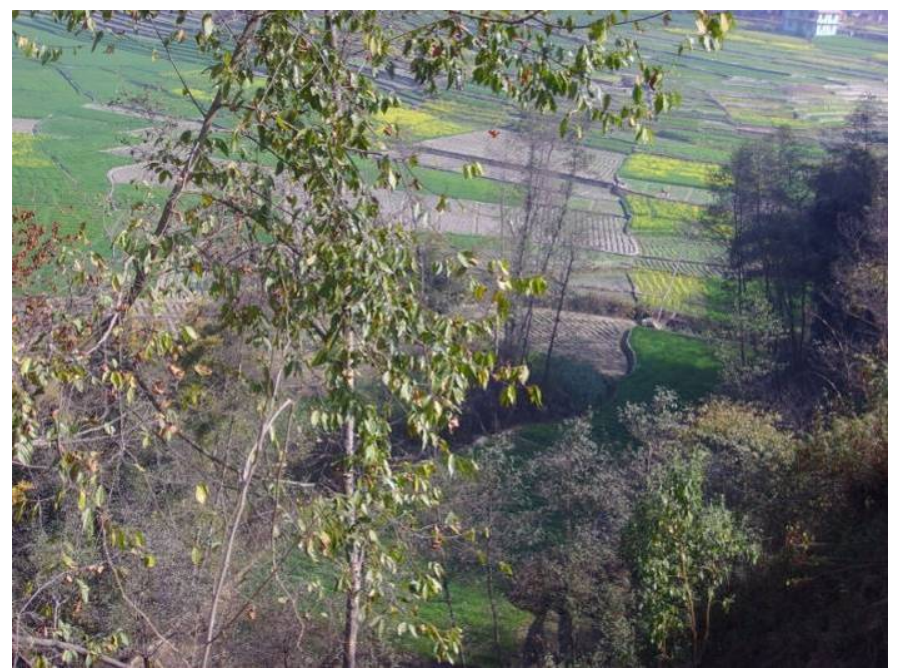

Figure 3. Commercial inorganic farming in the peri-urban lowland

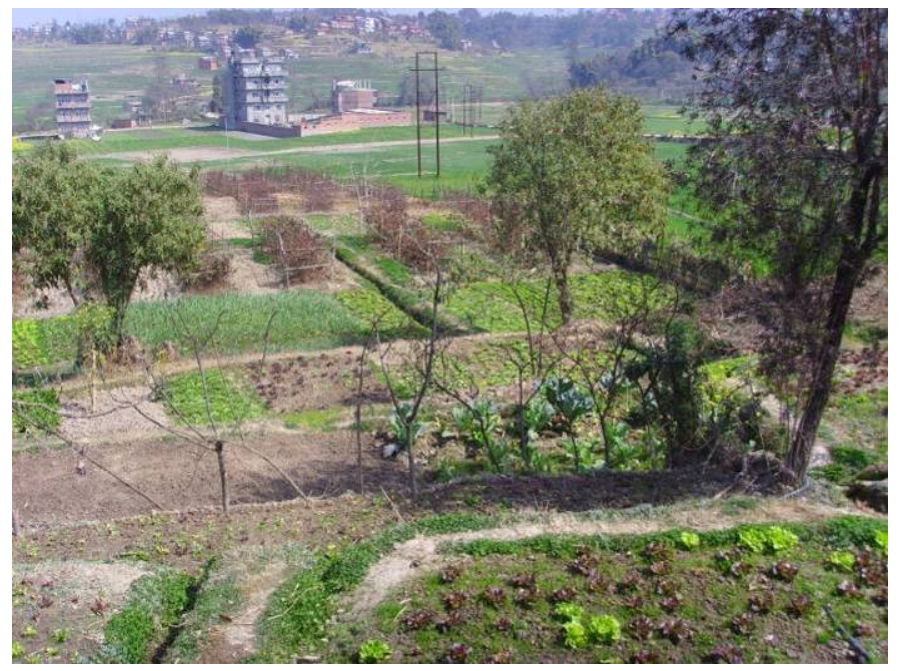

Figure 4. Smallholder organic vegetables farm in the urban area 


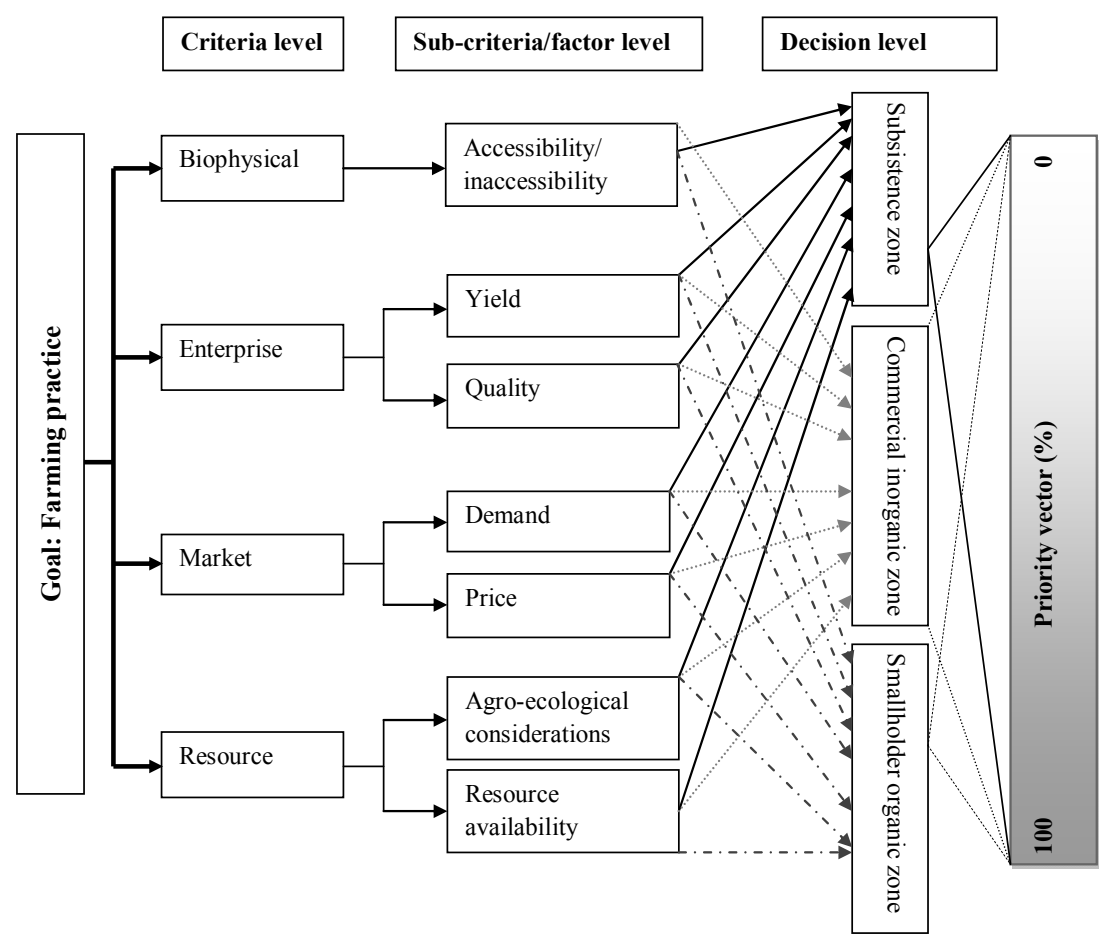

Figure 5. Different criteria and sub-criteria under investigation and their hierarchy

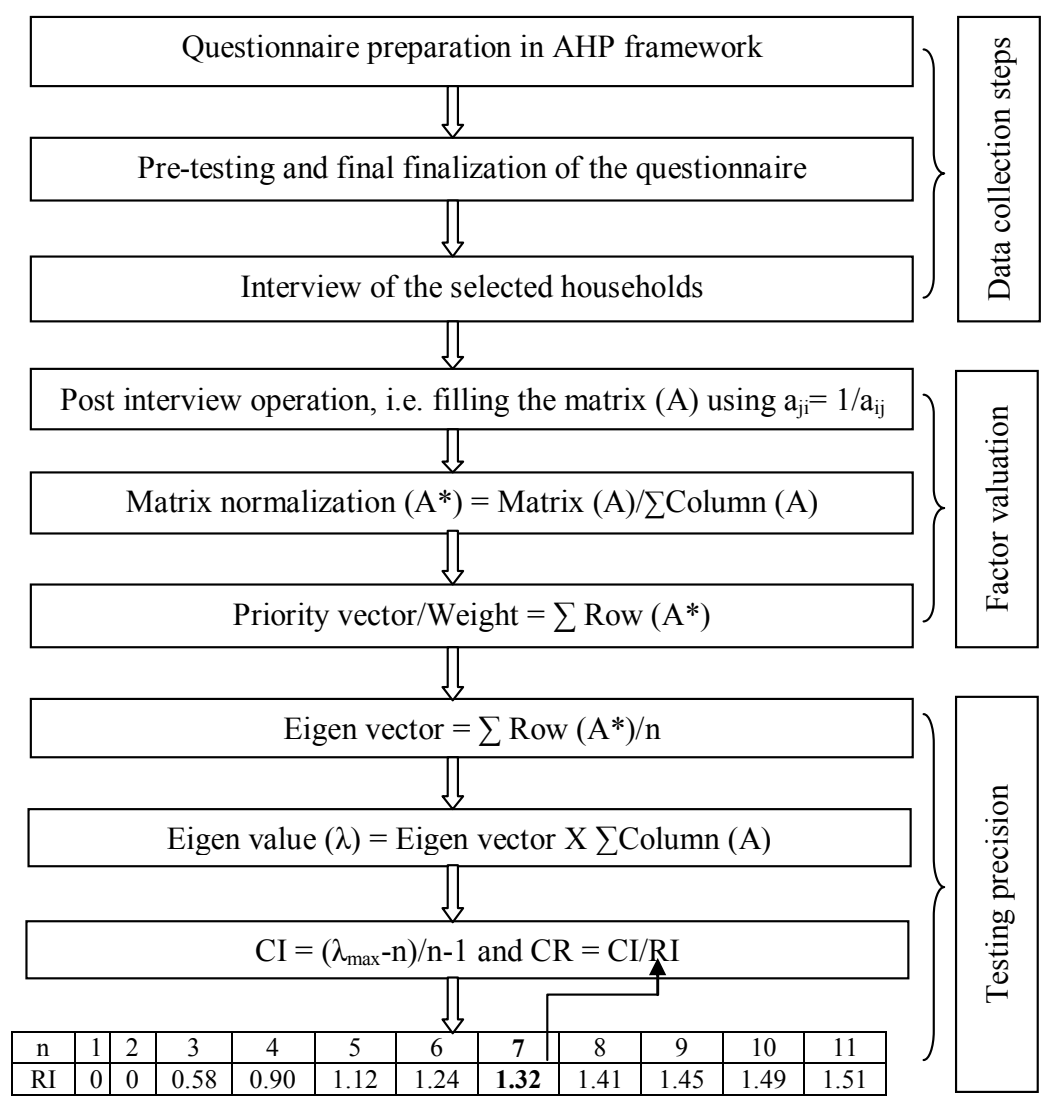

Figure 6. Modeling driving factors of production practices in the rural-urban interface via AHP framework 


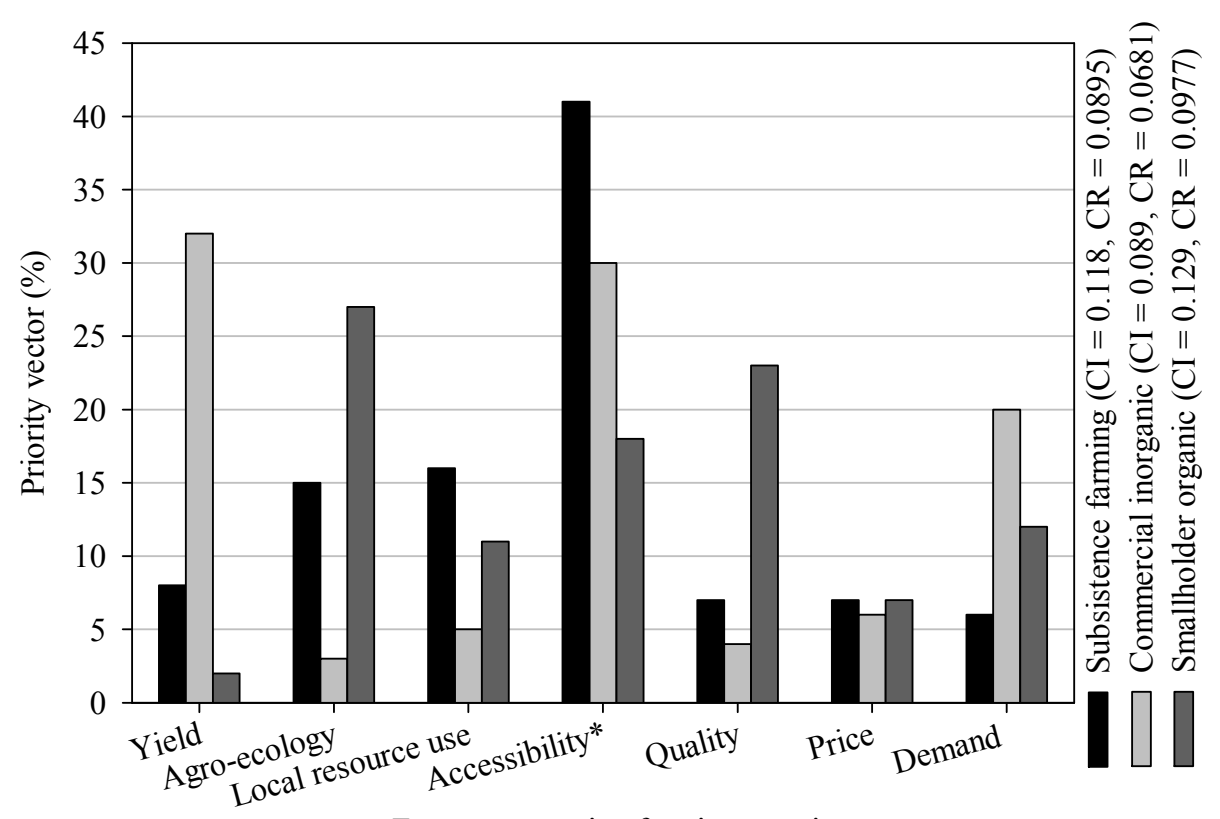

Factors governing farming practice

Figure 7. Priority vector (\%) of the factors along with consistency index in the three farming zones

*In subsistence zone, inaccessibility was included in the AHP framework and judgment evaluation was done accordingly

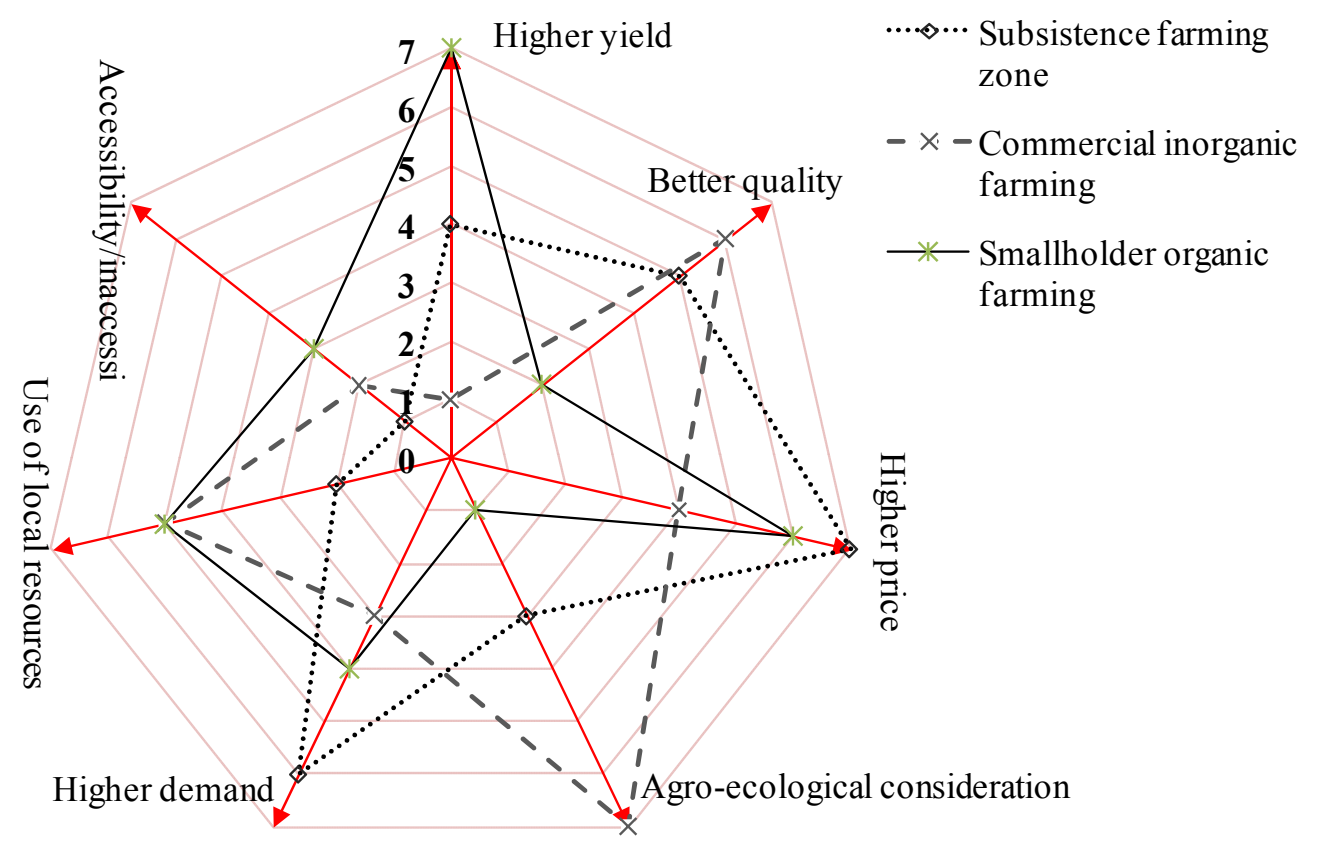

Figure 8. Ranking different factors of farming differentiation in the rural-urban interface of the Kathmandu Valley 